\title{
Evaluation of Polychlorinated biphenyls (PCBs) in Iranian dairy products (yogurt, doogh and kashk) by modified QuEChERS extraction and GC- QqQ- MS/MS method: a health risk assessment study
}

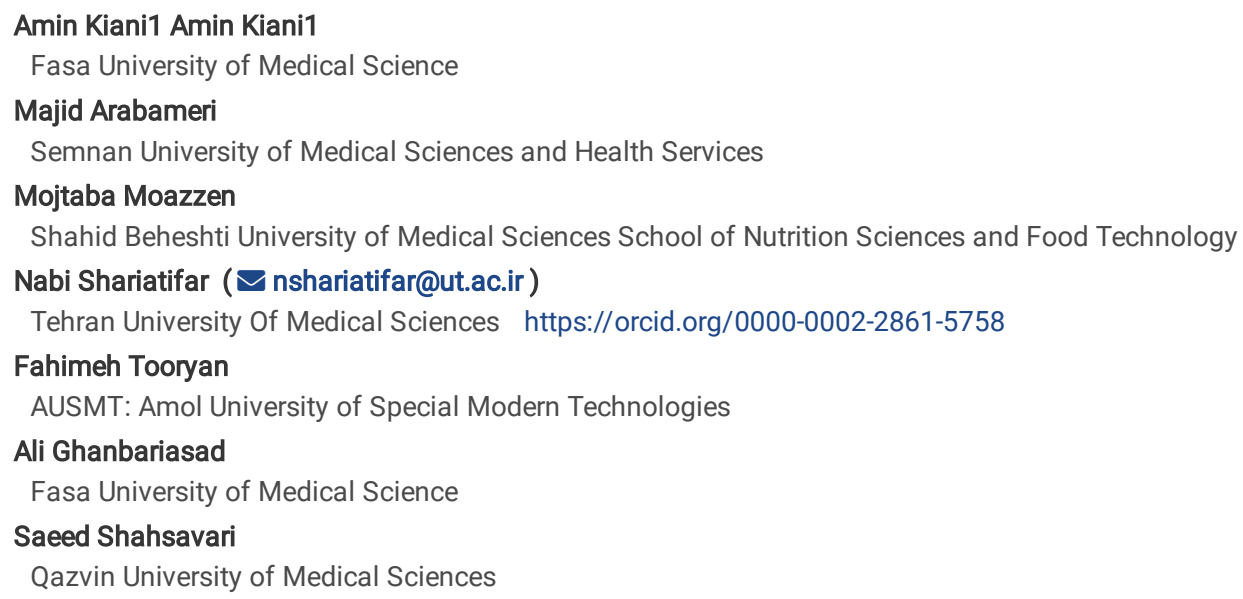




\section{Abstract}

The levels of 6 NDL-PCBs (non-dioxin-like-polychlorinated biphenyls) of were measured in some of Iranian dairy products (yogurt, doogh and kashk). A total of 120 samples were evaluated by modified QuEChERS extraction and gas chromatography-triple-quadrupole mass spectrometry (GC-QqQ-MS/MS) method, also

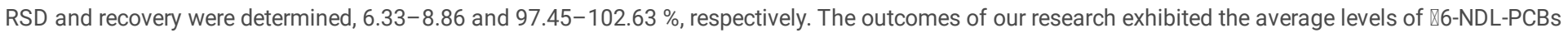
in all samples were $15.17 \pm 3.44 \mathrm{ng} / \mathrm{g}$ fat that were lower than the standard level established by EU ( $40 \mathrm{ng} / \mathrm{g}$ fat). Also, results showed kashk samples had maximum mean level of 6-NDL-PCBs $(18.66 \pm 2.42 \mathrm{ng} / \mathrm{g}$ fat) and doogh samples had minimum mean level of 6-NDL-PCBs (12.21 $\pm 2.22 \mathrm{ng} / \mathrm{g}$ fat). The mean level of 6-NDL-PCBs in yogurt samples was $14.65 \pm 2.02 \mathrm{ng} / \mathrm{g}$ fat. The heat map results depicted the correlation between spectral indicators 6-NDL-PCBs in different dairy products. A risks assessment based on the Monte Carlo method was done by calculating the Estimated Daily Intake (EDI) and Incremental Life Cancer Risk (ILCR) by the technique of Monte Carlo. The EDI values of 6 NDL-PCBs based on the 95 percentile in yogurt, doogh and kashk were 14.3, 1.49 and $0.5 \mathrm{ng} / \mathrm{kg}$.day, respectively. According to the calculated 95 percent ILCR, dietary exposure to 6 NDL-PCBs does not pose a risk to Iranian consumer health.

\section{Introduction}

People are always exposed to different types of anthropogenic substances. Some chemicals are rapidly eliminated in the human body, while others are stored and gradually metabolized. PCBs are one of the substances that are stored in the body for a long time (Ahmadkhaniha et al. 2017, Ahmadloo et al. 2019, Yaminifar et al. 2021). PCBs are produced by chlorinating aromatics (12-68\%), and some are commercially known as Araclor, Phenoclor and Clophen. There are 209 PCBs, among which 12 are dioxin-like PCBs (dl-PCBs) (PCB-189, -169, -167, -157, -156, -126, -123, -118, -114, -105, -81 and PCB-77). Six PCBs (PCB $-180,-153,-138,-101,-52$ and PCB-28) have been selected as indicator PCBs (in- PCBs) for residue monitoring in the environment and in foods (Adekunte et al., Amiridou \&Voutsa 2011, Bordajandi et al. 2004, Costabeber et al. 2018).

PCB exposure has been related to immunological and neurobehavioral abnormalities in children, as well as diabetes and cancers. The IARC (International Agency for Research on Cancer) and The WHO (World Health Organization's) has classified DDT, HCB and HCH as group 2B, possible carcinogenic substances for humans and PCBs as 2A, probable carcinogenic substances (Ahmadkhaniha et al. 2017, Ahmadloo et al. 2019, Đeđibegović et al. 2019).

The route sources of exposure to dioxins and PCBs are the skin, inhalation of air, drinking water and food in humans. Among these, diet is one of the most important sources of routes to PCBs (Ahmadkhaniha et al. 2017, Cheney et al. 2019, Costabeber et al. 2018, Elangovan et al. 2019).

Milk and dairy products (yogurt, butter, cheese, cream, buttermilk and kashk) are the main sources of human exposure to PCBs due to their regular use in every meal. PCBs enter the body of milk-producing livestock mainly through the consumption of contaminated water and forage (Özdemir et al. 2019 , Roszko et al. 2014, Saktrakulkla et al. 2020, Schecter et al. 2010).

Yogurt is a well-known product obtained from the fermentation of milk. Two products made directly from yogurt include doogh and kashk (Kiani et al. 2018, Shiroodi et al. 2012).

Doogh is a traditional dairy-based beverage made from a combination of yogurt set or stirred, water and salt. Despite the fact that doogh (yogurt-based drink) is widely drunk around the world, particularly in Asia, there are clear distinctions between it and comparable products used in Europe owing to the variation in viscosity and the presence of salt (Kiani et al. 2018, Kiani et al. 2019, Kouhpayeh et al. 2017).

Humans have known for thousands of years that drying causes food to be stored for longer. For example, the main purpose of preparing yogurt in powder form (kashk) is easy and stable maintenance of the product. kashk is a concentrated boiled doogh or yogurt that contains a salt additive that comes in flat or round rolls and then dries in the presence of air (Iranmanesh et al. 2018, Shiroodi et al. 2012).

Today, many techniques are applied to detect PCBs in food products, such as GC with an electron capture detector (ECD), GC-MS, GC-QqQ-MS/MS and GC coupled with high-resolution mass spectrometry (GC-HRMS). Among them, GC-QqQ-MS/MS has high sensitivity, high accuracy and has many applications in this field (Reddy et al. 2019, Yaminifar et al. 2021).

For evaluation of PCBs and other contaminants in food products, a method was introduced in 2003 that was quick, easy, cheap, effective, rugged, and safe (QuEChERS) QuEChERS technique is used to extract analytes from food matrix due to its fast, cheap, simple, etc (Özdemir et al. 2019, Rutkowska et al. 2018).

In Iran, contamination of farms and pastures with petroleum and chemical compounds in various ways is one of the most important causes of PCB contamination of dairy products. Considering the lack of a comprehensive study on the evaluation of PCB concentrations in dairy products such as yogurt, kashk, and doogh (in Iran and around the world), as well as the relatively high consumption of these products in the basket of Iranian, determining the level of $6 \mathrm{NDL}-\mathrm{PCBs}$ in these samples is critical. The aim of current research to evaluate the health risk and measure the concentration of 6 NDL-PCBs by using modified QuEChERS (quick, easy, cheap, effective, rugged, and safe) extraction and by GC-QqQ-MS/MS technique in kinds of dairy products (yogurt, doogh and kashk) and estimated the possible health risk posed by dairy products ingestion.

\section{Materials And Methods}

\subsection{Sample collection}

A total number of 40 samples of yogurt, 40 samples of doogh and 40 samples of kashk were analyzed. These samples have been obtained from the market of Tehran, Iran.

\subsection{Chemicals and reagents}


The PCBs analytical standards with a purity degree more than 99\% (PCB 180, 2,2',3,4,4',5,5'-heptachlorobiphenyl; PCB 138, 2,2',3,4,4',5'-hexachlorobiphenyl; PCB 153, 2,2',4,4',5,5'-hexachlorobiphenyl; PCB 101, 2,2',4,5,5'-Pentachlorobiphenyl; PCB 52, 2,2',5,5'-tetrachlorobiphenyl and PCB 28, 2,4,4'-trichlorobiphenyl) were obtained from Sigma-Aldrich (USA). Methylbenzene, acetonitrile, methyl alcohol, MgSO4, toluene, primary secondary amine (PSA) and NaCl were obtained from Merck Co. (Germany).

\subsection{Preparation of standard solution}

Thirty two microliters of the solution of original standard (10 ng/ $\mu \mathrm{L}$ of 6 PCBs with EC Number of 208-759-1) to prepare the standard stock solution was transferred with a micropipette to laboratory dishes and reaches to $10 \mathrm{~mL}$ volume with toluene (Yaminifar et al. 2021).

\subsection{Preparation of sample}

The yogurt, doogh and kashk samples preparation were performed by using a QuEChERS modified method. First, $5 \mathrm{~g}$ of samples was homogenized and poured into a $50 \mathrm{~mL}$ tube (glassy). Afterward, acetonitrile $(20 \mathrm{~mL})$ and $10 \mu \mathrm{L}$ of internal standard (PCB29 with a concentration of $10 \mathrm{ng} / \mathrm{mL}) \mathrm{were}$ added and mixed with vortex. Afterward $6 \mathrm{mg}$ of $\mathrm{MgSO}_{4}$ and $\mathrm{NaCl}(2: 1)$ were added to tube (glassy) and shaken by vortex (vigorously). The solution (for ten minutes) was centrifuged at $5000 \mathrm{rpm}$. Then, the above solution ( $10 \mathrm{~mL}$ ) was poured into a $15 \mathrm{~mL}$ vial (glassy). Next, the solution was placed (for fifteen minutes) in a freezer at $-20^{\circ} \mathrm{C}$. Then, $400 \mathrm{mg}$ primary secondary amine (PSA), $40 \mathrm{mg} \mathrm{C18}$ and $1 \mathrm{~mL}$ toluene were added to vial (glassy). Afterward, poured into a glass tube and shaken for 30 seconds with a vortex and standing for 5 minutes. Finally, one microliter was injected to GC-MS/MS (Xizhi Wang 2016).

\subsection{Analytical conditions and instrumentals}

The 6 NDL-PCB congeners were evaluated by GC-MS/MS device (Shimadzu GCMS-TQ8040). For separation of 6 NDL-PCBs the column Rxi-5 MS, 30 meters $\times$ 0.25 millimeters $\times 0.25$ micrometers was applied. The column oven temp was $50^{\circ} \mathrm{C}(1 \mathrm{~min})-25^{\circ} \mathrm{C}$ per minutes- $125^{\circ} \mathrm{C}-10^{\circ} \mathrm{C}$ per minutes-300 ${ }^{\circ} \mathrm{C}(3.5 \mathrm{~min})$. The Splitless was mode of injection and temperature of injection was $250^{\circ} \mathrm{C}$. The argon was gas of CID and the mode of flow control was linear velocity $(47.2$ $\mathrm{cm} / \mathrm{sec}$ ). The voltage of detector was tuning result $+0.6 \mathrm{kv}$. The temperature of ion source and interface were $200^{\circ} \mathrm{C}$ and $250{ }^{\circ} \mathrm{C}$, respectively $(X i z h i$ Wang 2016).

\subsection{Quantification method}

The quantification of method (precision, recovery, accuracy, linearity, LOQ, LOD and analysis by the GC-MS-MS) were performed according to our previous study (Yaminifar et al.).

\subsection{Assessment of human health risk}

The present study examined the daily intake and carcinogenic risks owing to the Iranian dairy products consumption (yogurt, doogh and kashk) contaminated with PCB. The model for computing risk was performed according to the previous report (Shariatifar et al. 2021, Yaminifar et al. 2021). Briefly, the average daily intake is used to measure the oral exposure of harmful materials and assessed by the following equation (Kiani et al. 2021a, Kiani et al. 2021b) :

$$
E D I=\frac{C \times E D \times E F \times I R}{B W \times A T}
$$

In this equation, estimated daily intake (EDI) is based on the $\mathrm{ng} / \mathrm{kg}$.day (Eghbaljoo-Gharehgheshlaghi et al. 2020), C is the PCB concentration based on $\mathrm{ng} / \mathrm{g}$ fat, the definition and description of the above variables are shown in Table 3. To evaluate the cancer risk of exposure of PCB compounds, the incremental lifetime carcinogenic risk (ILCR) model was obtained by the following equation (Kiani et al. 2021a).

$\mathrm{ILCR}=\mathrm{EDI} \times \mathrm{SF}$ Equation (2)

By the guidance of US EPA, where SF is equal to $2 \mathrm{mg} / \mathrm{Kg}$ b.w. per day for PCBs was referenced (Falandysz et al. 1999). The definition and description of variables are shown in Table 3.

\subsection{Statistical analysis}

By using SPSS (ver. 25), a practical and easy statistical analysis was utilized for the values of standard deviation (SD), mean, maximum and minimum. The test of Kolmogorov Smirnov was used to evaluate normal distribution of continuous variables. ANOVA, independent $t$ test, Mann Whitney and Kruskal-Wallis were utilized to evaluate differences between groups. The P-value less than 0.05 was selected as the significant difference for all tests. A data visualization procedure was conducted to explain the correlation among the variables and highlight dairy products' contamination. (Arabameri et al. 2019, Moradi et al. 2021). The Heat map was performed in evaluating the relationships contamination among samples (yogurt, doogh and kashk) online at the site of https://biit.cs.ut.ee/clustvis/.

\section{Results And Discussion}

\subsection{Analytical method evaluation performance}

The analytical characteristics of the applied technique for analysis of PCB compounds displayed in Table 2. The results displayed the LOQs and LODs for the PCB analytes varied $0.180-0.360$ and $0.06-0.12 \mathrm{ng} / \mathrm{g}$ fat, respectively. Also, the percent of RSD and recovery of the 6 NDL-PCBs analyte was determined at a range of $6.33-8.86$ and $97.45-102.63 \%$, respectively.

\subsection{Evaluation of PCBs in dairy product samples}


Table 3 are showed statistical analysis of our results, which displays mean, max, and min of each PCB analytes in yogurt, doogh and kashk samples. The outcomes of our research exhibited the average levels of $₫ 6-N D L-P C B s$ in all samples were $15.17 \pm 3.44 \mathrm{ng} / \mathrm{g}$ fat that were lower than the standard levels established by EU (40 ng/g fat). The maximum mean level was PCB180 ( $9.98 \pm 2.04 \mathrm{ng} / \mathrm{g}$ fat) and minimum mean level of PCBs in samples was PCB28 (0.09 $\pm 0.06 \mathrm{ng} / \mathrm{g}$ fat).

It is noteworthy that so far no studies have been done on the amount of these contaminants (PCBs) in doogh and kashk, only a few studies have been done on yogurt and other dairy products, which are mentioned below:

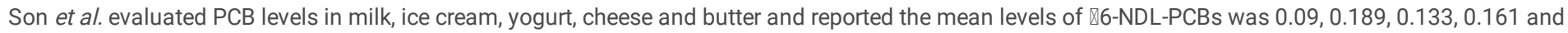
$0.449 \mathrm{ng} / \mathrm{g}$ fat, respectively that were less than present outcomes (Son et al. 2012). Schecter et al. evaluated PCBs in samples of frozen yogurt, cheese and cream cheese, whole milk, butter and ice cream and reported the mean levels of $₫ 6$-NDL-PCBs was non-detected (ND) in all samples which were lower than present results (Schecter et al. 2010). Witczak A et al. assessed PCB levels in milk and yoghurt samples in Poland and exposed the mean level of the IIndicator-PCBs was 1.858 and $1.754 \mathrm{ng} / \mathrm{g}$ fat, respectively that were less than present study (Witczak \&Mituniewicz-Małek 2019). Yaminifar et al. measured PCB levels in butter samples in Iran and showed the mean levels of $\triangle N D L-P C B s$ was $21.701 \pm 9.02 \mathrm{ng} / \mathrm{g}$ fat, which was upper than this study (Yaminifar et al. 2021). Uçar et al. assessed PCB levels in samples of butter and reported the average of $\triangle 6 \mathrm{NDL}-\mathrm{PCBs}$ was between $0.20-3.04 \mathrm{ng} / \mathrm{g}$ fat that was less than the outcomes of this research (Uçar et al. 2011). Cimenci et al. evaluated PCB levels in samples of butter and milk and reported the median level of $₫ 6$ NDL-PCBs was $4.72 \mathrm{ng} / \mathrm{g}$ fat for both of them which were less than present outcomes (Cimenci et al. 2013). Santos J. et al. assessed PCB concentrations in samples of industrialized and homemade cheese in Brazil and reported the mean level of the $\Sigma$ Indicator-PCBs was $33.32 \pm 25.40 \mathrm{ng} / \mathrm{g}$ fat and $26.58 \pm 9.91 \mathrm{ng} / \mathrm{g}$ fat, respectively that was upper than present outcomes (Santos et al. 2006). Pérez et al. evaluated PCB compounds in samples of milk in Mexico and reported the mean level of the $\Sigma$ Indicator-PCBs was $9.6 \mathrm{ng} / \mathrm{g}$ fat that was less than present outcomes (Pérez et al. 2012). Atmaca E evaluated levels of PCBs in samples of milk in Turkey and reported the mean levels of $₫ 6-N D L-P C B s$ was $127.27 \mathrm{ng} / \mathrm{g}$ fat which was higher than present research (Atmaca 2019). Miclean $\mathrm{M}$ et al. assessed PCB levels in samples of milk in Romania and reported the mean level of the $\Sigma$ Indicator-PCBs was $9.12 \mathrm{ng} / \mathrm{g}$ fat, which was less than present research (Miclean et al. 2018). Rusin et al. evaluated PCB levels in samples of milk and reported the mean level of the $\otimes 6$ NDL-PCBs was $1.25 \mathrm{ng} / \mathrm{g}$ fat that was less than the outcomes of this research (Rusin et al. 2019).

In comparison to other researchers, the outcomes of PCBs contaminate in this research revealed the environmental contaminant (water, soil and air) with pesticides, products of petroleum, contaminants from diesel trucks and paints may cause pollution of livestock feed and agricultural products like mentioned dairy products (yogurt, doogh and kashk). Additionally, the close proximity of farms of animal to the oil refineries, roads and industries may reason in livestock pollution, followed by livestock products like these dairy products. Generally, these compound levels (6 NDL-PCBs) in the samples of yogurt, doogh and kashk in Tehran city that was less than the standard levels stablished by EU.

\subsection{Evaluation of PCBs in kinds of dairy products samples (yogurt, doogh and kashk)}

The outcomes exhibited in the Table 4 showed the level of 6 NDL-PCBs in kinds of dairy product samples. Our outcomes showed that kashk samples had maximum mean level of 6-NDL-PCBs $(18.66 \pm 2.42 \mathrm{ng} / \mathrm{g}$ fat) and doogh samples had minimum mean level of 6-NDL-PCBs (12.21 $\pm 2.22 \mathrm{ng} / \mathrm{g}$ fat). The mean level of 6-NDL-PCBs in yogurt samples was $14.65 \pm 2.02 \mathrm{ng} / \mathrm{g}$ fat. So, in all samples level of 6-NDL-PCBs were lower the EU standard level (40 $\mathrm{ng} / \mathrm{g}$ fat). Since doogh is obtained by diluting yogurt and kashk from concentrating yogurt, the reason for the lower results of doogh and the higher results of kashk can probably be explained. Therefore, it can be stated that with the concentration of dairy products, the amount of PCBs compound should probably increase as well, although the amount of this increase will not be dangerous for the consumer because it is less than the existing standards. Son et al., Schecter et al. and Witczak A et al. evaluated PCB concentrations in yogurt samples and reported the mean level of $₫ 6$-NDL-PCBs were 0.133 , ND and 1.754 ng/g fat, respectively that were less than this research (Schecter et al. 2010, Son et al. 2012, Witczak \&Mituniewicz-Małek 2019).

\subsection{Evaluation of PCBs in different brands}

The outcomes revealed that in Table 5 showed, which the level of 6 NDL-PCBs in different brands of dairy product samples. The results showed brand A had the maximum mean level of $6 \mathrm{NDL}-\mathrm{PCBs}(18.23 \pm 3.32 \mathrm{ng} / \mathrm{g}$ fat) and brand $\mathrm{E}$ had the minimum mean level of $6 \mathrm{NDL}-\mathrm{PCBs}(12.93 \pm 2.78 \mathrm{ng} / \mathrm{g}$ fat). The reason for the higher level of PCBs in a brand $\mathrm{E}$ can be the use of more polluted livestock fodder, the supply of milk from contaminated environments, the proximity of the factory to urban and industrial centers, the proximity of livestock to contaminated environments and the use of contaminated containers and equipment.

\subsection{Human health risk assessment}

The results presented in the table 6 show the daily intake of 6 NDL-PCBs in dairy product samples. The yogurt had the maximum mean daily intake of 6 NDLPCBs (1.43ng/kg day) and Kashk had the minimum mean daily intake of 6 NDL-PCBs (5.09E- $1 \mathrm{ng} / \mathrm{kg}$ day). The reason for the higher consumption of yogurt in Tehran (Iran) was associated with an increased risk of NDL-PCBs daily intake. The rank order of 6 NDL-PCBs EDI value based on percentile $95 \%$ in yogurt was PCB 180 (2.99E-5)>PCB 153 (1.35E-5)>PCB 138 (1.59E-6)>PCB 52 (4.42E-7)>PCB 28 (2.82E-7) >PCB 101(2.79E-7); in Doogh was PCB 180 (I2.54E-6) >PCB 153(1.08E-6) >PCB 138 (1.28E-7) >PCB 52 (3.68E-8) >PCB 101 (2.43E-8) >PCB 28 (2.34E-8); in Kashk was PCB 180 (1.11E-6)>PCB 153 (4.80E-7)>PCB 138 (5.25E-8) >PCB 52 (1.51E-8)>PCB 28 (1.10E-8) >PCB 101(1.10E-8).

The average dietary exposure to NDL-PCBs was far below the WHO's tolerable daily intake (10 ng/kg BW/day) for the general population (Dinc et al. 2019). The EDI distribution among PCBs congeners with the most and least contribution is shown in Fig. 1. In all samples, PCB180 became the most important congener.

Previous studies assessed 6 NDL-PCBs levels in Cow milk from Silesia Province, Poland and exposed the mean level of the 6 NDL-PCBs was $2.1 \mathrm{ng} / \mathrm{kg}$ day (Rusin et al. 2019). In China, Kang et al. noted that dietary exposure to PCBs in food was $26.47 \mathrm{ng} / \mathrm{kg}$ day than our investigation (Kang et al. 2020). Also, Chung et al. reported in Hong Kong the less and higher bound on the intake of PCBs was 0.68 and 1.38 ng/kg day (Chung et al., 2018). The people studied in 
Poland were moreover more exposed to NDL-PCB compounds than in the current research. These variations are mostly due to different levels of environmental pollution with persistent organic pollutants and different sources of these compounds' emissions. Other key diet components were not included in the estimates since they were based only on the use of dairy products. As a result, the total health risk from dietary exposure to a complete diet is likely to be upper.

The results presented in the Fig. 2 show the amount of ILCR in different dairy product samples. The ILCR values from the Monte Carlo simulation showed yogurt samples had maximum mean level of ILCR (4.63E-5) and doogh samples had minimum mean level of ILCR (1.63E-6) that exhibited there potency be a low risk of oral cancer for people in Iran.

The cancer risk of PCBs for target population was much smaller than the unacceptable risk $\left(10^{-4}\right)$. The oral cancer risk of 6 NDL-PCBs was lower than the unacceptable limit $\left(10^{-4}\right)$ for people in Iran. Rusin et al. measured total of 18 PCBs (that consist of 6 NDL-PCBs) in popular foods of animal origin that the mean cancer risk resulting from eggs, chicken meat and farm-fresh cow milk intake $6.9 \times 10^{-3}, 3.4 \times 10^{-4}$ and $2.8 \times 10^{-4}$, respectively that was upper than this research (Rusin et al. 2019).

\subsection{Analysis based on heat map results}

The heat map provides a profile overview of the largest and smallest data in the matrix by clustering similar parameters. The dairy product contamination to PCB congeners was visually stated as a heat map for each sample. The patterns of heat map were markedly various depending on the PCB congener. The first cluster includes PCB 138 and PCB 153, Second cluster contains two sub-groups. The cluster dendrogram is shown in Fig. 3. As the Euclidean space reductions, the samples showed a higher correlation. Hence, PCB 180, PCB 131, and PCB 52 had a high correlation among different samples (yogurt, doogh, and kashk).

\section{Conclusion}

Conclusively, this study was the first to compare 6 NDL-PCBs residues in kinds of dairy products (yogurt, doogh and kashk) samples of Tehran. The samples were analyzed using modified QuEChERS and by GC-QqQ-MS/MS method which had a very good performance in this regard with recovery more than $97.45 \%$. Our study showed PCB contaminant levels were higher in kashk samples and lower in doogh samples (kashk>yogurt>doogh). The 6 NDL-PCB levels in all samples was less than the EU standard level. The dietary exposure to NDL-PCBs detected in dairy products was much lowers the recommended TDI (10 ng/kg BW/day). The Monte Carlo simulation output exhibited the index of ILCR owing to ingestion of 6-NDL-PCBs lower than the safe level (ILCR $>1 \mathrm{E}-4$ ). It is suggested that more control and monitoring be done on dairy products due to high consumption and high sensitivity of these products and other similar studies should be done in other dairy products.

\section{Declarations}

Acknowledgment: This study was carry out by the researchers in the Fasa University of Medical Sciences and Health Services (With grant no 99301).

Competing interests: Authors of this article state there is no competitive interest.

Ethical Approval: "This study does not involve any human or animal testing" or "This study was approved by the Fasa University of Medical Sciences and Health Services

Consent to participate: All authors participated in present research.

Consent to publish; All authors agree to publish.

Data availability: The datasets used and/or analyzed during the current study are available from the corresponding author on reasonable request.'

Author's contributions: Nabi Shariatifar: Conceptualization, Supervision, Design of study, Writing- Reviewing and Editing. Ali Ghanbariasad: Design of study, Writing- Reviewing and Editing. Mojtaba Moazzen:Data curation, Writing- Reviewing and Editing. Majd Arabameri: Visualization, Investigation, Saftware, Methodology. Software, Validation, Amin Kiani: Methodology. Software, Validation, Maryam Moazzen: Data curation, Writing- Original draft preparation, Fahimeh Tooryan: Design of study, Writing- Reviewing and Editing. Saeed Shahsavari: Saftware, Methodology

\section{References}

1. Adekunte A, Tiwari B, O’Donnell C Probabilistic modelling of dioxins and dioxin-like PCBs consumed in dairy products. An accept-and-reject algorithm to determine performance objectives that comply with a food safety objective,348

2. Ahmadkhaniha R, Nodehi RN, Rastkari N, Aghamirloo HM (2017) Polychlorinated biphenyls (PCBs) residues in commercial pasteurized cows' milk in Tehran, Iran. Journal of Environmental Health Science and Engineering 15:1-6

3. Ahmadloo M, Shariatifar N, Mahmoudi R, Qajarbeygi P, Moazzen M, Akbarzadeh A, Nazmara S, Dobaradaran S (2019) Assessment of polychlorinated biphenyls concentration in egg using GC-MS method. Journal of Mazandaran University of Medical Sciences 28:69-81

4. Amiridou D, Voutsa D (2011) Alkylphenols and phthalates in bottled waters. J Hazard Mater 185:281-286

5. Arabameri M, Nazari RR, Abdolshahi A, Abdollahzadeh M, Mirzamohammadi S, Shariatifar N, Barba FJ, Mousavi Khaneghah A (2019) Oxidative stability of virgin olive oil: evaluation and prediction with an adaptive neuro-fuzzy inference system (ANFIS). J Sci Food Agric 99:5358-5367 
6. Atmaca E (2019) BIOMONITORING OF SOME PERSISTENT ORGANOCHLORINE CONTAMINANTS IN THE MILK OF ANATOLIAN WATER BUFFALOES. GIda 44:348-356

7. Bordajandi LR, Gómez G, Abad E, Rivera J, Fernández-Bastón MdM, Blasco J, González MJ (2004) Survey of persistent organochlorine contaminants (PCBs, PCDD/Fs, and PAHs), heavy metals ( $\mathrm{Cu}, \mathrm{Cd}, \mathrm{Zn}, \mathrm{Pb}$, and $\mathrm{Hg}$ ), and arsenic in food samples from Huelva (Spain): levels and health implications. J Agric Food Chem 52:992-1001

8. Cheney D, Logan JM, Gardner K, Sly E, Wysor B, Greenwood S (2019) Bioaccumulation of PCBs by a seaweed bloom (Ulva rigida) and transfer to higher trophic levels in an estuarine food web. Mar Ecol Prog Ser 611:75-93

9. Cimenci O, Vandevijvere S, Goscinny S, Van Den Bergh M-A, Hanot V, Vinkx C, Bolle F, Van Loco J (2013) Dietary exposure of the Belgian adult population to non-dioxin-like PCBs. Food Chem Toxicol 59:670-679

10. Costabeber IH, Coelho AN, Schwanz TG, Weis GCC, Carpilovsky CK (2018) : Levels of polychlorinated biphenyls (PCBs) in whole milk powderand estimated daily intake for a population of children. Ciência Rural 48

11. Đeđibegović JJ, Turalić AA, Ajdinović NN, Marjanović AA, Omeragić EE, Čaušević AA, Čaklovica FF, Šober MM (2019) Preliminary data on polychlorinated biphenyls (PCBs) in cows' milk from Bosnia and Herzegovina market. Food and Feed Research 46:45-50

12. Dinc H, Atmaca E, Das YK, Aksoy A (2019) A DETERMINATION OF ORGANOCHLORINE COMPOUNDS IN BUTTER SAMPLES FROM SOUTH-EASTERN TURKEY. Fresenius Environ Bull 28:5973-5981

13. Eghbaljoo-Gharehgheshlaghi H, Shariatifar N, Arab A, Alizadeh-Sani M, sani IK, Asdagh A, Rostami M, Alikord M, Arabameri M (2020) : The concentration and probabilistic health risk assessment of trace metals in three type of sesame seeds using ICP- OES in Iran. International Journal of Environmental Analytical Chemistry, $1-15$

14. Elangovan S, Pandian SBS, Geetha S, Joshi SJ (2019) Polychlorinated biphenyls (PCBs): Environmental fate, challenges and bioremediation, Microbial Metabolism of Xenobiotic Compounds. Springer, pp 165-188

15. Falandysz J, Strandberg B, Strandberg L, Rappe C (1999) Tris (4-chlorophenyl) methane and tris (4-chlorophenyl) methanol in sediment and food webs from the Baltic south coast. Environ Sci Technol 33:517-521

16. Iranmanesh M, Ezzatpanah H, Akbari-Adergani B, Karimi Torshizi MA (2018) SPME/GC-MS characterization of volatile compounds of Iranian traditional dried Kashk. Int J Food Prop 21:1067-1079

17. Kang Y, Cao S, Yan F, Qin N, Wang B, Zhang Y, Shao K, El-maleh CA, Duan X (2020) Health risks and source identification of dietary exposure to indicator polychlorinated biphenyls (PCBs) in Lanzhou, China. Environ Geochem Health 42:681-692

18. Kiani A, Ahmadloo M, Shariatifar N, Moazzen M, Baghani AN, Khaniki GJ, Taghinezhad A, Kouhpayeh A, Mousavi Khaneghah A, Ghajarbeygi P (2018) Method development for determination of migrated phthalate acid esters from polyethylene terephthalate (PET) packaging into traditional Iranian drinking beverage (Doogh) samples: a novel approach of MSPE-GC/MS technique. Environmental Science and Pollution Research

19. Kiani A, Shariatifar N, Shahsavari S, Ahmadloo M, Moazzen M (2019) Investigating the presence of polycyclic aromatic hydrocarbons in Doogh. Journal of Mazandaran University of Medical Sciences 29:10-23

20. Kiani A, Ahmadloo M, Moazzen M, Shariatifar N, Shahsavari S, Arabameri M, Hasani MM, Azari A, Abdel-Wahhab MA (2021a) Monitoring of polycyclic aromatic hydrocarbons and probabilistic health risk assessment in yogurt and butter in Iran. Food Science \& Nutrition 9:2114-2128

21. Kiani A, Arabameri M, Moazzen M, Shariatifar N, Aeenehvand S, Khaniki GJ, Abdel-Wahhab M, Shahsavari S (2021b) : Probabilistic health risk assessment of trace elements in baby food and milk powder using ICP-OES method.Biological Trace Element Research,1-12

22. Kouhpayeh A, Moazzen M, Jahed Khaniki GR, Dobaradaran S, Shariatifar N, Ahmadloo M, Azari A, Nazmara S, Kiani A, Salari M (2017) Extraction and determination of phthalate esters (PAEs) in Doogh. Journal of Mazandaran University of medical sciences 26:257-267

23. Miclean M, Cadar O, Levei E, Todea D (2018) : Human health risk assessment of organochlorine compounds associated with raw milk consumption in a Romanian industrial area.Italian Journal of Food Science30

24. Moradi M, Bolandi M, Arabameri M, Karimi M, Baghaei H, Nahidi F, Eslami Kanafi M (2021) Semi-volume gluten-free bread: effect of guar gum, sodium caseinate and transglutaminase enzyme on the quality parameters. Journal of Food Measurement and Characterization

25. Özdemir C, Özdemir S, Oz E, Oz F (2019) : Determination of organochlorine pesticide residues in pasteurized and sterilized milk using QuEChERS sample preparation followed by gas chromatography-mass spectrometry.Journal of Food Processing and Preservation43, e14173

26. Pérez JJ, y León SV, Gutiérrez R, López Y, Faure R, Escobar A (2012) Polychlorinated biphenyls (PCBs) residues in milk from an agroindustrial zone of Tuxpan. Veracruz Mexico Chemosphere 89:404-408

27. Reddy AVB, Moniruzzaman M, Aminabhavi TM (2019) Polychlorinated biphenyls (PCBs) in the environment: Recent updates on sampling, pretreatment, cleanup technologies and their analysis. Chem Eng J 358:1186-1207

28. Roszko M, Szymczyk K, Rzepkowska M, Jędrzejczak R (2014) Seasonal variability of polychlorinated biphenyls (PCBs) and polychlorinated diphenyl ethers (PBDEs) congener profiles in butter in Poland: Dietary risk evaluation. Journal of Environmental Science and Health Part B 49:182-199

29. Rusin M, Dziubanek G, Marchwińska-Wyrwał E, Ćwieląg-Drabek M, Razzaghi M, Piekut A (2019) PCDDs, PCDFs and PCBs in locally produced foods as health risk factors in Silesia Province, Poland. 172:128-135Ecotoxicology and environmental safety

30. Rutkowska E, Łozowicka B, Kaczyński P (2018) Modification of multiresidue QuEChERS protocol to minimize matrix effect and improve recoveries for determination of pesticide residues in dried herbs followed by GC-MS/MS. Food Anal Methods 11:709-724

31. Saktrakulkla P, Lan T, Hua J, Marek RF, Thorne PS, Hornbuckle KC (2020) Polychlorinated biphenyls in food. Environ Sci Technol 54:11443-11452

32. Santos J, Xavier A, Ries E, Costabeber I, Emanuelli T (2006) Assessment of polychlorinated biphenyls (PCBs) in cheese from Rio Grande do Sul, Brazil. Chemosphere 65:1544-1550

Page 6/11 
33. Schecter A, Colacino J, Haffner D, Patel K, Opel M, Päpke O, Birnbaum L (2010) : Perfluorinated compounds, polychlorinated biphenyls, and organochlorine pesticide contamination in composite food samples from Dallas, Texas, USA. Environmental health perspectives 118, 796-802

34. Shariatifar N, Moazzen M, Arabameri M, Moazzen M, Khaniki GJ, Sadighara P (2021) Measurement of polycyclic aromatic hydrocarbons (PAHs) in edible mushrooms (raw, grilled and fried) using MSPE-GC/MS method: a risk assessment study. Applied Biological Chemistry 64:1-11

35. Shiroodi SG, Mohammadifar MA, Gorji EG, Ezzatpanah H, Zohouri N (2012) Influence of gum tragacanth on the physicochemical and rheological properties of kashk. J Dairy Res 79:93-101

36. Son M-H, Kim J-T, Park H, Kim M, Paek O-J, Chang Y-S (2012) Assessment of the daily intake of 62 polychlorinated biphenyls from dietary exposure in South Korea. Chemosphere 89:957-963

37. Uçar Y, Traag W, Immerzeel J, Kraats C, van der Lee M, Hoogenboom R, van der Weg G, Cakirogullari GC, Oymael B, Kilic D (2011) Levels of PCDD/Fs, PCBs and PBDEs in butter from Turkey and estimated dietary intake from dairy products. Food Additives and Contaminants: Part B 4:141-151

38. Witczak A, Mituniewicz-Małek A (2019) The impact of bacterial cultures on changes in contents of PCB congeners in yoghurt and bioyoghurt-alternative methods for PCB reduction in dairy products. Mljekarstvo/Dairy 69

39. Xizhi Wang SL, Tian F, Yang JFanG, Huang T, Kawano Shin-ichi (2016)Yuki Hashi: Research of Polychlorinated Biphenyls (PCBs) in Vegetables by GCMS/MS. Pittcon 2016 (shimadzu corporation) PO-CON1622E

40. Yaminifar S, Aeenehvand S, Ghelichkhani G, Ahmadloo M, Arabameri M, Moazzen M, Shariatifar N The measurement and health risk assessment of polychlorinated biphenyls in butter samples using the QuEChERS/GC-MS method.International Journal of Dairy Technology n/a

41. Yaminifar S, Aeenehvand S, Ghelichkhani G, Ahmadloo M, Arabameri M, Moazzen M, Shariatifar N (2021) The measurement and health risk assessment of polychlorinated biphenyls in butter samples using the QuEChERS/GC-MS method. International Journal of Dairy Technology

\section{Tables}

Table 1

Parameters applied in the present study for health exposure assessment in dairy products

\begin{tabular}{|llll|}
\hline \multicolumn{2}{|l|}{ exposure parameters } & unit & Reference \\
\hline SF & carcinogenic slope factor of oral intake $(2)$ & $\left(\mathrm{mg}\left(\mathrm{kg} \mathrm{d}^{-1}\right)\right)^{-1}$ & (Kang et al. 2020) \\
\hline C & concentrations of PCBs & $\mu \mathrm{g} / \mathrm{Kg}$ & - \\
\hline EDI & estimated daily intake & $\mathrm{mgkg}-1$ & (Karimi et al. 2021) \\
\hline EFi & exposure frequency & days per year & (Seilani et al. 2021) \\
\hline IR & Average daily intake & $\mathrm{Kg} / \mathrm{day}$ & (Karami et al. 2021) \\
\hline ED & exposure duration & days & (Roudbari et al. 2021) \\
\hline AT & average time & days & (Cheney et al. 2019) \\
\hline BW & body weight (for children and adults is between 15 and 70) & $\mathrm{kg}$ & (Shariatifar et al. 2020) \\
\hline
\end{tabular}

Table 2

The linear range of concentration, LOQ, LOD, recovery, RSD, inter-day and intra-day reproducibility of validation method.

\begin{tabular}{|lllllllll|}
\hline Compound & Linear range of concentration $(\mathbf{n g} / \mathbf{m L})$ & $\begin{array}{l}\text { LOD } \\
(\mathbf{n g} / \mathbf{g})\end{array}$ & $\begin{array}{l}\text { LOQ } \\
(\mathbf{n g} / \mathbf{g})\end{array}$ & RSD\% & Recovery\% & Intra-day & Inter-day \\
\hline PCB 28 & $0.10-40$ & 0.080 & 0.250 & 6.33 & 100.21 & 7.55 & 10.58 \\
\hline PCB 52 & $0.10-40$ & 0.080 & 0.250 & 8.86 & 102.63 & 10.34 & 14.92 \\
\hline PCB 101 & $0.10-40$ & 0.120 & 0.360 & 7.54 & 98.49 & 11.44 & 13.81 \\
\hline PCB 138 & $0.10-40$ & 0.060 & 0.180 & 7.49 & 97.45 & 9.58 & 14.98 \\
\hline PCB 153 & $0.10-40$ & 0.100 & 0.310 & 8.55 & 101.38 & 10.81 & 15.22 \\
\hline PCB 180 & $0.10-40$ & 0.080 & 0.250 & 8.29 & 98.97 & 11.83 & 15.94 \\
\hline
\end{tabular}


Table 3

Statistical analysis of PCBs in dairy product samples (ng/g fat)

\begin{tabular}{|lllll|}
\hline & Minimum & Maximum & Mean & Std. Deviation (SD) \\
\hline PCB 28 & 0.04 & 0.26 & 0.09 & 0.06 \\
\hline PCB 52 & 0.04 & 0.9 & 0.19 & 0.21 \\
\hline PCB 101 & 0.06 & 0.18 & 0.1 & 0.05 \\
\hline PCB 138 & 0.24 & 0.76 & 0.48 & 0.15 \\
\hline PCB 153 & 2.65 & 6.75 & 4.33 & 1.23 \\
\hline PCB 180 & 6.28 & 13.42 & 9.98 & 2.04 \\
\hline Total & 9.62 & 21.71 & 15.17 & 3.44 \\
\hline \multicolumn{5}{c}{ Table 4 } \\
\hline
\end{tabular}

Statistical analysis of PCBs in kinds of dairy products ( $\mathrm{ng} / \mathrm{g}$ fat)

\begin{tabular}{|c|c|c|c|c|c|c|c|c|c|c|c|c|c|}
\hline \multirow[t]{2}{*}{ Type } & \multicolumn{4}{|c|}{ Yogurt } & \multicolumn{4}{|c|}{ Doogh } & \multicolumn{5}{|l|}{ Kashk } \\
\hline & Min & Max & Mean & SD & Min & Max & Mean & SD & Min & Max & Mean & SD & $P$ value \\
\hline РСВ 28 & 0.04 & 0.15 & 0.09 & 0.05 & 0.04 & 0.11 & 0.06 & 0.03 & 0.04 & 0.26 & 0.13 & 0.08 & 0.82 \\
\hline РСВ 52 & 0.04 & 0.24 & 0.14 & 0.07 & 0.04 & 0.9 & 0.25 & 0.37 & 0.09 & 0.34 & 0.17 & 0.1 & 1 \\
\hline РСB 101 & 0.06 & 0.13 & 0.09 & 0.04 & 0.06 & 0.14 & 0.08 & 0.04 & 0.06 & 0.18 & 0.12 & 0.06 & 0.33 \\
\hline РСВ 138 & 0.41 & 0.61 & 0.5 & 0.08 & 0.24 & 0.45 & 0.34 & 0.09 & 0.41 & 0.76 & 0.61 & 0.14 & 0.33 \\
\hline РСВ 153 & 3.24 & 5.88 & 4.26 & 0.99 & 2.65 & 4.07 & 3.33 & 0.62 & 4.21 & 6.75 & 5.41 & 1.09 & 0.33 \\
\hline РСB 180 & 8.64 & 10.88 & 9.58 & 0.93 & 6.28 & 9.74 & 8.14 & 1.36 & 10.82 & 13.42 & 12.21 & 1.1 & 0.08 \\
\hline Total & 12.59 & 17.89 & 14.65 & 2.02 & 9.62 & 15.09 & 12.21 & 2.22 & 15.87 & 21.71 & 18.66 & 2.42 & 0.08 \\
\hline
\end{tabular}

Table 5

Statistical analysis of PCBs in different brands of dairy products ( $\mathrm{ng} / \mathrm{g}$ fat)

\begin{tabular}{|c|c|c|c|c|c|c|c|c|c|c|c|c|c|c|}
\hline \multirow[t]{2}{*}{ brand } & \multicolumn{3}{|l|}{ A } & \multicolumn{3}{|l|}{ B } & \multicolumn{3}{|l|}{ C } & \multicolumn{3}{|l|}{ D } & \multicolumn{2}{|l|}{$E$} \\
\hline & Min & Max & Mean $\pm S D$ & Min & Max & Mean $\pm S D$ & Min & Max & Mean $\pm S D$ & Min & Max & Mean $\pm S D$ & Min & Max \\
\hline $\begin{array}{l}\text { PCB } \\
28\end{array}$ & 0.11 & 0.26 & $0.17 \pm 0.08$ & 0.04 & 0.04 & $0.04 \pm 0.00$ & 0.04 & 0.09 & $0.07 \pm 0.03$ & 0.09 & 0.12 & $0.11 \pm 0.02$ & 0.04 & 0.15 \\
\hline $\begin{array}{l}\text { PCB } \\
52\end{array}$ & 0.24 & 0.9 & $0.49 \pm 0.36$ & 0.12 & 0.17 & $0.15 \pm 0.03$ & 0.04 & 0.09 & $0.06 \pm 0.03$ & 0.13 & 0.16 & $0.14 \pm 0.02$ & 0.04 & 0.11 \\
\hline $\begin{array}{l}\text { PCB } \\
101\end{array}$ & 0.13 & 0.18 & $0.15 \pm 0.03$ & 0.06 & 0.14 & $0.11 \pm 0.04$ & 0.06 & 0.06 & $0.06 \pm 0.00$ & 0.06 & 0.06 & $0.06 \pm 0.00$ & 0.06 & 0.17 \\
\hline $\begin{array}{l}\text { PCB } \\
138\end{array}$ & 0.45 & 0.76 & $0.61 \pm 0.16$ & 0.34 & 0.64 & $0.49 \pm 0.15$ & 0.41 & 0.7 & $0.55 \pm 0.15$ & 0.27 & 0.52 & $0.42 \pm 0.13$ & 0.24 & 0.41 \\
\hline $\begin{array}{l}\text { PCB } \\
153\end{array}$ & 3.75 & 6.75 & $5.46 \pm 1.54$ & 3.44 & 5.66 & $4.48 \pm 1.12$ & 4.05 & 6.06 & $4.73 \pm 1.15$ & 2.76 & 4.39 & $3.64 \pm 0.82$ & 2.65 & 4.21 \\
\hline $\begin{array}{l}\text { PCB } \\
180\end{array}$ & 9.74 & 13.42 & $11.35 \pm 1.88$ & 8.83 & 12.51 & $10.36 \pm 1.92$ & 8.54 & 12.97 & $10.05 \pm 2.53$ & 6.28 & 11.35 & $9.18 \pm 2.61$ & 7.31 & 10.82 \\
\hline Total & 15.09 & 21.71 & $18.23 \pm 3.32$ & 12.83 & 19.16 & $15.63 \pm 3.23$ & 13.16 & 19.97 & $15.52 \pm 3.86$ & 9.62 & 16.58 & $13.55 \pm 3.56$ & 10.34 & 15.87 \\
\hline
\end{tabular}

Table 6. Simulation results for EDI of NDL-PCBs detected in dairy products (yogurt, doogh and kashk). 


\begin{tabular}{|c|c|c|c|c|c|c|c|c|}
\hline & Percentiles & РCB 28 & РCB 52 & РСВ 101 & РСB 138 & РСВ 153 & РСB 180 & Total NDL-PCB \\
\hline \multirow[t]{4}{*}{ Yogurt } & $5 \%$ & $5.96 \mathrm{E}-2$ & $9.15 \mathrm{E}-2$ & $6.01 \mathrm{E}-2$ & $3.30 \mathrm{E}-1$ & $2.78 \mathrm{E}+0$ & $6.18 \mathrm{E}+0$ & $9.72 \mathrm{E}+0$ \\
\hline & $50 \%$ & 8.91E-2 & 1.37E-1 & 8.74E-2 & 4.95E-1 & $4.16 \mathrm{E}+0$ & $9.26 \mathrm{E}+0$ & 1.43E+1 \\
\hline & $75 \%$ & $1.06 \mathrm{E}-1$ & $1.62 \mathrm{E}-1$ & $1.03 \mathrm{E}-1$ & $5.79 \mathrm{E}-1$ & 4.87E+0 & $1.09 \mathrm{E}+1$ & $1.68 \mathrm{E}+1$ \\
\hline & $95 \%$ & $1.32 \mathrm{E}-1$ & $2.09 \mathrm{E}-1$ & $1.27 \mathrm{E}-1$ & $7.28 \mathrm{E}-1$ & $6.19 \mathrm{E}+0$ & $1.45 \mathrm{E}+1$ & $2.12 \mathrm{E}+1$ \\
\hline \multirow[t]{4}{*}{ Doogh } & $5 \%$ & $3.32 \mathrm{E}-3$ & $1.38 \mathrm{E}-2$ & $4.31 \mathrm{E}-3$ & $1.88 \mathrm{E}-2$ & $1.78 \mathrm{E}-1$ & 4.43E-1 & $6.54 \mathrm{E}-1$ \\
\hline & $50 \%$ & 4.89E-3 & $2.06 \mathrm{E}-2$ & $6.42 \mathrm{E}-3$ & $2.76 \mathrm{E}-2$ & $2.68 \mathrm{E}-1$ & $6.68 \mathrm{E}-1$ & $1.01 \mathrm{E}+0$ \\
\hline & $75 \%$ & $5.79 \mathrm{E}-3$ & $2.40 \mathrm{E}-2$ & $7.63 E-3$ & 3.32E-2 & 3.17E-1 & $7.79 \mathrm{E}-1$ & 1.19E+0 \\
\hline & $95 \%$ & $7.40 \mathrm{E}-3$ & $3.08 \mathrm{E}-2$ & 9.57E-3 & $4.11 \mathrm{E}-2$ & 4.05E-1 & $9.65 \mathrm{E}-1$ & $1.49 \mathrm{E}+0$ \\
\hline \multirow[t]{4}{*}{ Kashk } & $5 \%$ & $2.36 \mathrm{E}-3$ & $3.00 \mathrm{E}-3$ & $2.16 \mathrm{E}-3$ & $1.11 \mathrm{E}-2$ & $9.60 \mathrm{E}-2$ & $2.21 \mathrm{E}-1$ & $3.40 \mathrm{E}-1$ \\
\hline & $50 \%$ & $3.52 \mathrm{E}-3$ & $4.54 \mathrm{E}-3$ & $3.25 \mathrm{E}-3$ & $1.70 \mathrm{E}-2$ & 1.47E-1 & 3.34E-1 & $5.09 \mathrm{E}-1$ \\
\hline & $75 \%$ & 4.19E-3 & $5.35 \mathrm{E}-3$ & $3.85 \mathrm{E}-3$ & $1.99 \mathrm{E}-2$ & 1.72E-1 & $3.94 \mathrm{E}-1$ & $6.05 \mathrm{E}-1$ \\
\hline & $95 \%$ & 5.33E-3 & $6.88 \mathrm{E}-3$ & $4.83 E-3$ & $2.57 \mathrm{E}-2$ & $2.20 \mathrm{E}-1$ & $5.02 \mathrm{E}-1$ & $7.66 \mathrm{E}-1$ \\
\hline
\end{tabular}

\section{Figures}
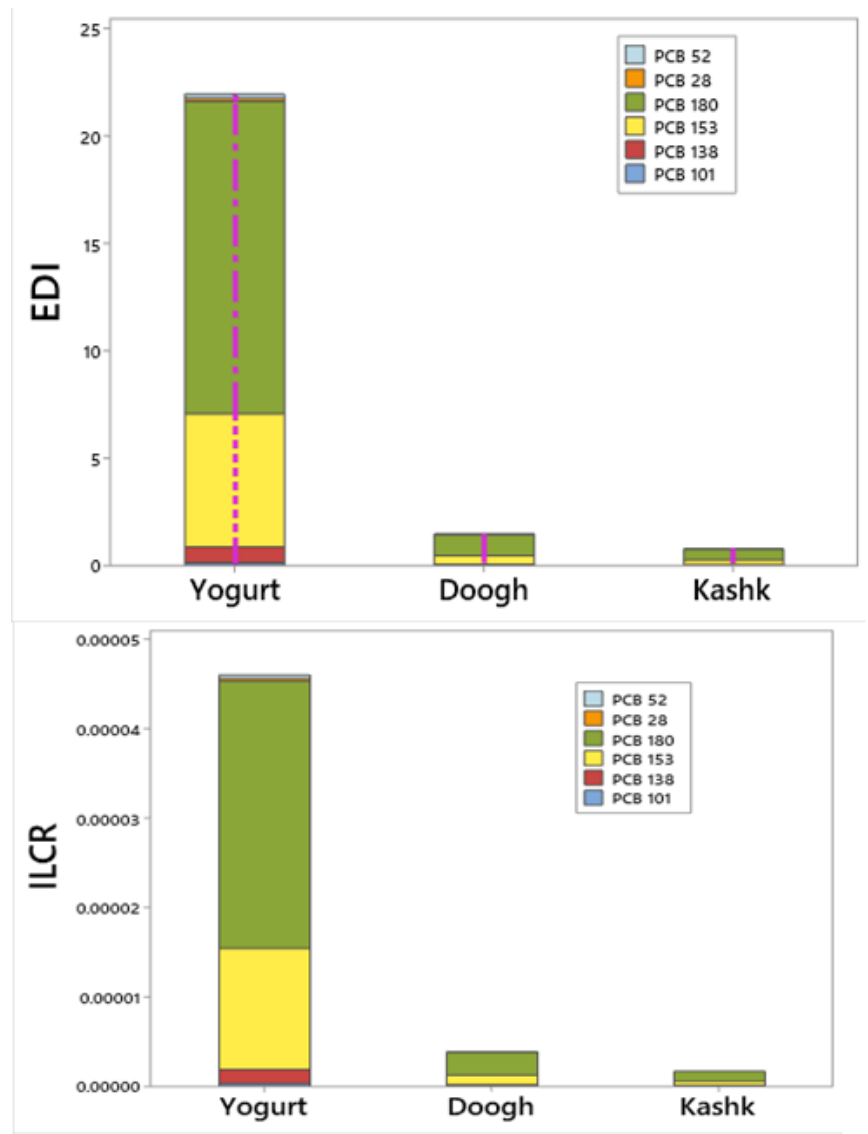

Figure 1

Contribution to overall EDI and ILCR in dairy products (yogurt, doogh and kashk). 

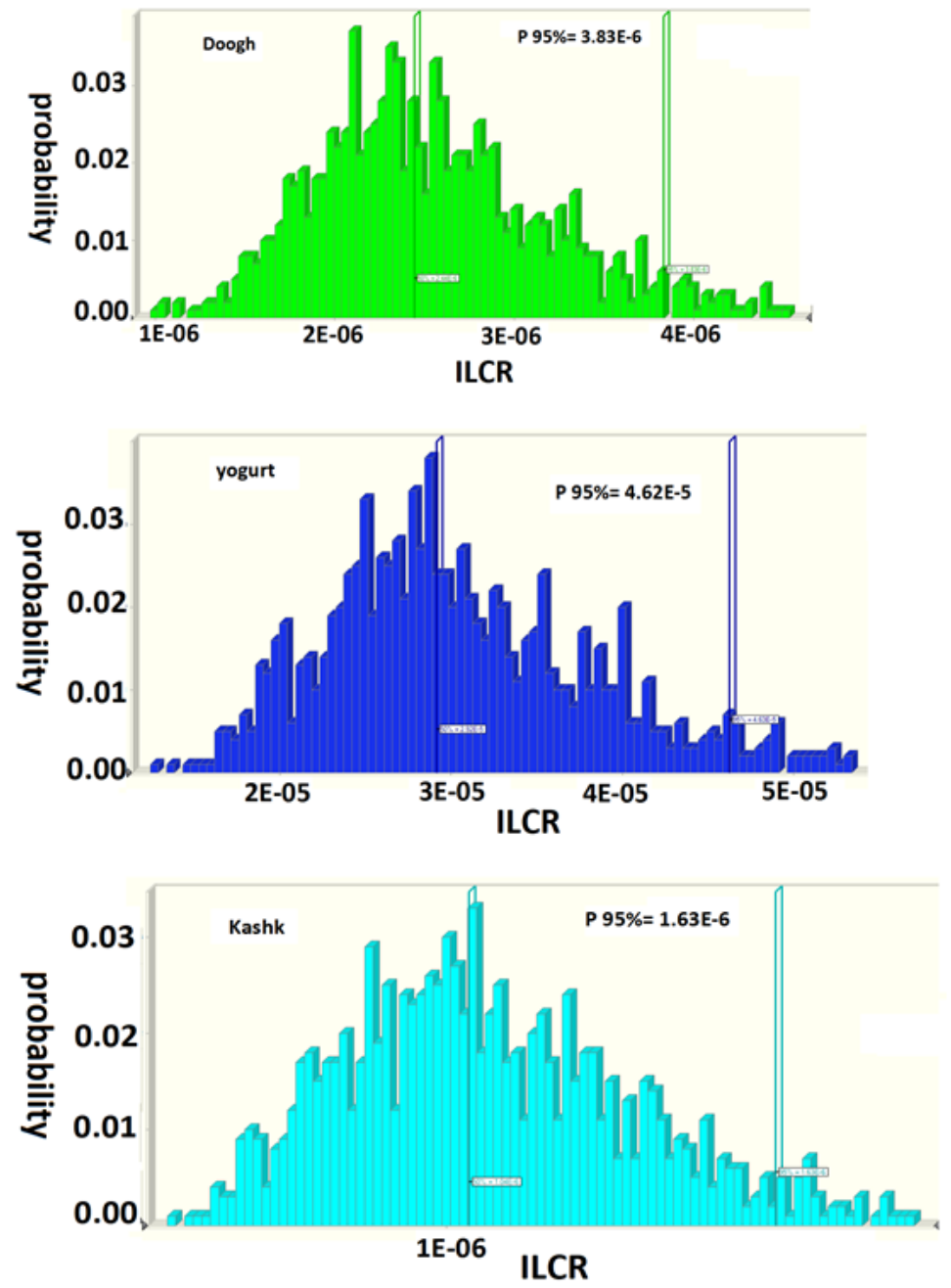

Figure 2

Simulation results for ILCR of NDL-PCBs detected in dairy products (yogurt, doogh and kashk).

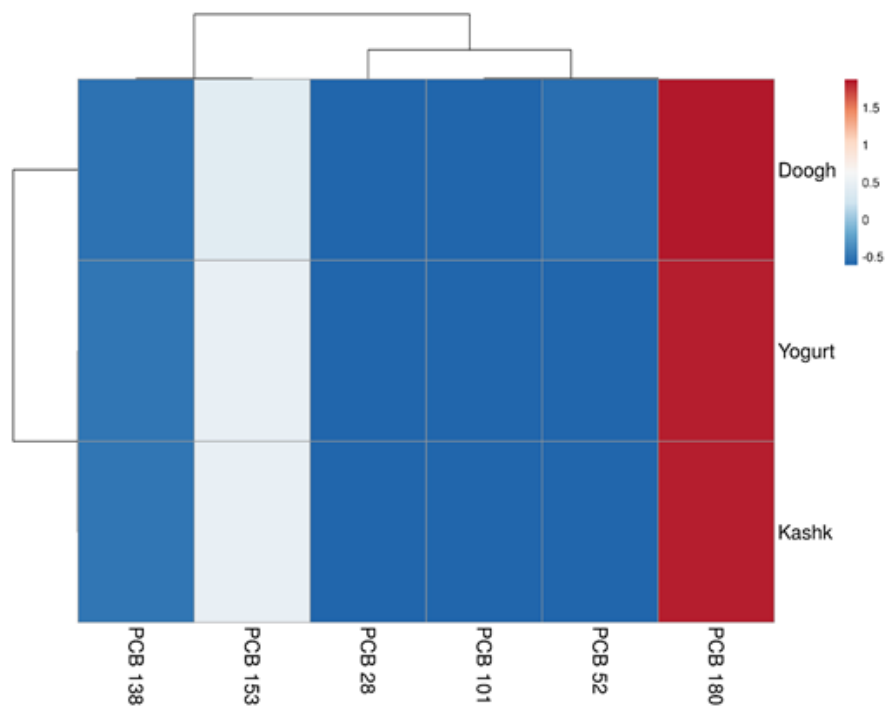

Figure 3

Heat map of 6NDL-PCBs in dairy products (yogurt, doogh and kashk). 
Page 11/11 